\title{
Riscos PsicossociaIs No TRABALHO
}

\section{Susana Pereira ${ }^{1}$ \\ Célia Ribeiro ${ }^{2}$}

\begin{abstract}
Resumo: Atualmente, os riscos psicossociais são reconhecidos por parte dos governos e instâncias nacionais, europeias e mundiais, como um dos maiores desafios para a saúde e segurança ocupacional, visto serem capazes de originar uma grave deterioração da saúde física e mental aos trabalhadores, acarretando consequências significativas para as organizações e para a sociedade. A necessidade de avaliação de riscos psicossociais surge num contexto de importantes transformações sociais, políticas, económicas e tecnológicas que têm impacto nas caraterísticas de trabalho e nas organizações do século XXI.
\end{abstract}

Palavras-chave: Riscos psicossociais, Trabalho, Fatores indutores

\section{PSYCHOSOCIAL RISKS AT WORK}

Abstract: Currently, psychosocial risks are recognized by governments and national, European and global fora, as one of the biggest challenges for occupational health and safety, as they are able for a serious deterioration of physical and mental health to workers resulting in significant consequences for organizations and society. The need for evaluation of psychosocial risks arises in the context of important social, political, economic and technological changes that have impact on the working characteristics and organizations of the XXI century.

Keywords: Psychosocial risks, Work, Inducing factors

\footnotetext{
${ }^{1}$ Doutoranda em Psicologia das Organizações, do Trabalho e dos Recursos Humanos. Técnica de Recursos Humanos. E-mail: scasp@sapo.pt

2 Doutorada em Psicologia, área de especialidade em Psicologia Pedagógica. Professora Auxiliar da Universidade Católica Portuguesa - Viseu. E-mail: cribeiro@viseu.ucp.pt
} 


\section{INTRODUÇÃO}

A saúde é uma ampla gama de possibilidades do organismo face às mais diversas situações que o ambiente coloca, "uma margem de tolerância às infidelidades do meio” (Canguilhem, 2009, p.78), então, ela é mais do que um estado, é um processo em permanente construção, com um equilíbrio precário (Costa \& Santos, 2013). É assim fundamental, ao considerar a saúde dos trabalhadores, se tenha em conta a globalidade dos riscos profissionais. A acumulação de conhecimentos científicos não tem impedido a persistência dos riscos no trabalho nem o agravamento dos constrangimentos organizacionais e no caso dos riscos psicossociais, especialistas de psicopatologia do trabalho, desde o início da década de 80, têm vindo a mostrar as repercussões que as diferentes dimensões do uso da saúde na atividade de trabalho têm sobre a saúde mental dos trabalhadores (Araújo \& Rolo, 2011; Ganem, 2011). O crescente e recente interesse pelos riscos psicossociais no trabalho justifica-se não só pelo seu aumento, mas também pelo incremento da sua visibilidade.

$\mathrm{O}$ aumento dos riscos psicossociais pode ser justificado por razões várias, relacionadas com as mudanças profundas do mercado laboral, refletidas no desenvolvimento de locais de trabalho que dão menor importância à capacidade física e mais às exigências psicossociais (Coelho, 2009).

O crescimento dos riscos psicossociais pode também ser justificado pelas mudanças no conceito de saúde que permitem, presentemente, afirmá-la como sendo algo global, conquistável e dependente de todos os aspetos da vivência do ser humano. Ou seja, a saúde é a capacidade de adaptação às condições de vida de ordem biológica, psicológica ou social, de criar novas condições para fazer face às agressões, não sendo a simples ausência da doença (Canguilhem, 2009). A atividade humana de trabalho e o fenómeno saúde-doença no trabalho são assim duas faces da mesma moeda, o que pressupõe que a diversidade das situações e das histórias individuais, no trabalho e face a uma atividade, configure campos diferentes de existência e de possibilidade de gestão pessoal dos riscos (Rosário, 2013). Torna-se então fundamental que, quando se considera a saúde dos trabalhadores, se tenha em conta a globalidade dos riscos, e sejam valorizados os diferentes constrangimentos que as situações e condições de trabalho implicam.

$\mathrm{O}$ recente interesse pelos riscos psicossociais corresponde mais a um "despertar" para a sua existência do que, propriamente, ao seu efetivo aparecimento, isto porque o conceito de risco psicossocial já está presente na literatura científica há várias décadas, vindo a ganhar maior visibilidade nos últimos vinte anos. 
Este interesse surge por estes riscos serem considerados emergentes, ou seja, de serem englobados numa classe de riscos nova e em crescimento, e a sua maior visibilidade decorre, ainda, e em parte considerável, da expressão riscos psicossociais ser vista, muitas vezes, como uma extensão do vocábulo stress (Costa \& Santos, 2013).

As questões ligadas ao ambiente de trabalho, à organização, caracterização e condições de trabalho, às oportunidades de desenvolvimento que este permite, ao balanço entre trabalho e vida fora dele, ao envelhecimento da população ativa e à precarização e insegurança no emprego, são, hoje em dia, consideradas fontes de riscos psicossociais. Constrangedoras das vivências, individual e relacional, estas condições são responsáveis pelo aumento da incidência de problemas físicos, abuso de substâncias, conflitos e violência, depressão e ansiedade (Cantera, Cervantes, \& Blanch, 2008; European Commission, 2010; EU-OSHA, 2010a).

Face ao exposto, o presente artigo tem como objetivo apresentar os principais fatores indutores dos riscos psicossociais, assim como as consequências e prevenção dos mesmos.

\section{RISCOS PSICOSSOCIAIS COMO RISCOS EMERGENTES}

De acordo com a Agência Europeia de Segurança e Saúde no Trabalho, risco emergente é «todo o risco que é novo e está a aumentar» (Rosário, 2013). O risco é considerado novo pois não era conhecido anteriormente e é causado por novos processos, novas tecnologias, novas configurações dos postos de trabalho ou pelas transformações sociais ou organizativas, ou quando um novo conhecimento científico possibilita que um antigo problema seja identificado como um risco (Coelho, 2009). Verifica-se que o risco está a aumentar, porque o número de perigos que conduzem ao risco está a crescer, a probabilidade de exposição ao risco está a aumentar, o efeito do perigo na saúde dos trabalhadores está a piorar (Agência Europeia, 2007).

Os riscos novos e emergentes têm chamado especial atenção, nos últimos anos, a diversos investigadores que têm desenvolvido estudos acerca das novas tendências dos acidentes de trabalho e os seus efeitos na saúde dos trabalhadores (Rosário, 2013).

A Agência Europeia para a Segurança e Saúde no Trabalho criou, em 2005, o Observatório Europeu dos Riscos com o objetivo de identificar novos riscos na segurança e saúde no trabalho e novas medidas eficazes de prevenção (Rosário, 2013). 
Num estudo efetuado entre 2003 e 2004, no âmbito dos riscos psicossociais, por um conjunto de peritos que representavam a União Europeia (UE), os Estados Unidos da América (EUA) e a Organização Internacional do Trabalho (OIT), é mencionado que num total de 42 riscos psicossociais no trabalho previsíveis, oito deles foram classificados como fortemente emergentes, 19 como emergentes, 14 como indecisos e um como não emergente (Agência Europeia, 2007). O estudo referiu ainda que os dez principais riscos psicossociais emergentes identificados estavam relacionados com os cinco aspetos do trabalho: novas formas de contratação e insegurança no trabalho, envelhecimento da população ativa, intensificação do trabalho, exigências emocionais elevadas e dificuldade na conciliação entre a vida profissional e familiar (Coelho, 2009; Rosário, 2013).

\section{DEFINIÇÃO DE RISCOS PSICOSSOCIAIS}

Na ausência de uma teoria consensual sobre o termo, no que diz respeito à sua definição, as diferentes disciplinas dão ênfase à organização do trabalho e, de maneira menos unânime, aos aspetos sociais e económicos, como o estatuto ou a renumeração (Costa \& Santos, 2013). Por um lado, consideram ser pertinente estudar, especificamente, os aspetos sociais do trabalho e o seu impacto sobre o psiquismo dos indivíduos mesmo que esses aspetos sociais possam interagir, também, com as condições físicas do trabalho e, por outro lado, consideram tanto os efeitos dos aspetos sociais do trabalho sobre a saúde mental, como sobre outras formas de saúde (Gollac \& Bodier, 2011).

Entre as inúmeras definições de risco psicossocial, destacam-se alguns exemplos: a Organização Internacional do Trabalho, em 1986, definiu os fatores psicossociais no trabalho como sendo fatores suscetíveis de influenciar a saúde dos trabalhadores, o rendimento e a satisfação no trabalho e que consiste por um lado, em interações entre o ambiente, conteúdo, natureza e as condições de trabalho, e por outro, as capacidades, necessidades, cultura e condições de vida do trabalhador fora do trabalho (OIT, 1986).

De acordo com a Organização Mundial da Saúde (OMS), os fatores psicossocias no trabalho podem ser definidos como os fatores que influenciando a saúde e o bem-estar do indivíduo e do grupo derivam da psicologia do indivíduo, da estrutura e da função da organização do trabalho. Compreendem aspetos sociais, tais como: as formas de interação 
no seio dos grupos, aspetos culturais, tais como os métodos tradicionais de resolução de conflitos, e aspetos psicológicos, como as atitudes, crenças e os traços de personalidade (OMS, 1981).

Para Cox e Cox (1993), estes riscos são os que resultam, por um lado, das interações do conteúdo, da organização do trabalho, dos sistemas de gestão e das condições ambientais e organizacionais, e por outro, as competências e necessidades dos trabalhadores. Estas interações podem gerar riscos para a saúde dos trabalhadores através das suas perceções e experiências. Para Cox e Griffiths (1995), os riscos psicossociais são todos os aspetos do desenho e gestão do trabalho e dos contextos social e organizacional com potencial para causar danos físicos ou psicológicos.

A Agência Europeia para a Segurança e Saúde no Trabalho (2007) define esses riscos como sendo aqueles aspetos do projeto de trabalho e da organização e gestão do trabalho, e seus contextos sociais e ambientais, que têm o potencial para causar dano psicológico, social ou físico. Ocaña e Rodriguez (2010) agrupam os riscos psicossociais em função da ausência, escassez ou excesso de determinadas condições em termos do trabalho e das quais advêm consequências para a saúde do trabalhador.

Gollac e Bodier (2011) referem que os riscos psicossociais são os riscos para a saúde criados pelo trabalho através de mecanismos sociais e psíquicos. Acrescentam que embora a noção de riscos psicossociais seja amplamente utilizada, ela não tem um significado claro e unívoco. Como o conceito de risco faz referência à exposição, por um lado, e aos danos por outro, é importante distinguir os fatores de risco dos seus efeitos sobre a saúde física, mental e social. Então, para os mesmos autores, deve ser levado em conta que o que faz com que um risco para a saúde no trabalho seja psicossocial, não é a sua manifestação, mas sim a sua origem, logo, os riscos psicossociais são definidos como os riscos para a saúde mental, física e social, originados pelas condições de trabalho e por fatores organizacionais e relacionais.

Ainda de acordo com Gollac e Bodier (2011), os fatores psicossociais de risco no trabalho podem ser agrupados em seis dimensões: a intensidade do trabalho e o tempo de trabalho; as exigências emocionais; a falta/insuficiência de autonomia; a má qualidade das relações sociais no trabalho; os conflitos de valores e a insegurança na situação de trabalho/emprego.

Mais recentemente, em 2012, na Campanha de Avaliação dos Riscos Psicossociais, promovida pelo Comité dos Altos Responsáveis pela Inspeção do Trabalho (Autoridade para as Condições do Trabalho - ACT, 
2012), os riscos psicossociais foram definidos como "os aspetos de programação de organização e gestão do trabalho, que em interação com os seus contextos sociais e ambientais, têm potencial para causar dano psicológico, social ou físico" (Agência Europeia, n.d., citado por CARIT, 2012, p. 2).

\section{FATORES INDUTORES DOS RISCOS PSICOSSOCIAIS}

Cada vez mais a sociedade atual se depara com um conjunto de transformações económicas, sociais e humanas a um ritmo cada vez mais acelerado, submetendo as empresas e os profissionais a novos desafios, face a riscos suscetíveis de prejudicar a saúde física e mental, especialmente os riscos de natureza psicossocial. São vários os fatores que contribuíram de forma determinante para esta situação, como o aumento da migração, a globalização, o desenvolvimento de novas tecnologias, a predominância do setor terciário, o envelhecimento da população ativa e da população em geral, o aumento do género feminino no trabalho e a mudança das condições de trabalho, o que leva consequentemente, a uma força de trabalho na qual os riscos psicossociais têm assumido um papel de destaque e de prioridade (Rosário, 2013).

As transformações nas condições do mercado de trabalho associadas ao aumento da competitividade, da carga de trabalho e da insegurança no trabalho, contribuem para um aumento na prevalência de fatores psicossociais adversos do trabalho.

Perante o contexto atual de crise mundial, os dados estatísticos têm revelado uma relação negativa crescente entre o aumento exponencial dos riscos e a saúde mental dos trabalhadores, tornando-se uma verdadeira problemática, que afeta quer as condições de trabalho quer o nível de satisfação e do bem-estar social e laboral dos mesmos (Rosário, 2013).

Vários são os esforços para demonstrar aos responsáveis pelas políticas de prevenção dos riscos profissionais que "prevenir os riscos nas empresas não é um gasto, mas sim um investimento produtivo” (UGT, 2011, n.p.), e que "sem a prevenção dos riscos da saúde mental, não pode haver saúde e sem saúde, não pode haver produtividade" (European Comission, 2007, n.p.). Assim, parte-se do princípio de que não é possível haver progresso económico sem saúde mental, sendo que a saúde não só é importante para o bem-estar dos indivíduos e da sociedade, mas uma população saudável é, também, um pré-requisito para a produtividade económica (Rosário, 2013). 
Verifica-se portanto que cada vez mais os riscos psicossociais no local de trabalho têm um possível impacto negativo sobre a saúde física, mental e social do trabalhador e ainda um papel direto e indireto do ambiente de trabalho psicossocial em índices de saúde organizacional (Rosário, 2013).

Importa assim referir que os riscos psicossociais têm sido reconhecidos como um dos principais problemas de saúde pública nos países industrializados (Leka \& Cox, 2008) e por isso, foram identificados como um dos principais desafios contemporâneos da segurança e saúde ocupacional estando relacionados sobretudo com problemas como o stress ocupacional, o burnout, o assédio (sexual e moral ou mobbing) e a violência no local de trabalho (Coelho, 2009; Rosário, 2013).

\subsection{Stress Ocupacional}

O stress ocupacional pode ser definido como "a reação que pode ter o indivíduo face às exigências e pressões do trabalho que não se ajustam aos seus conhecimentos e capacidades, e que põem à prova a sua capacidade de afrontar a situação" (Leka, Griffiths, \& Cox, 2003, p. 3), "um desequilíbrio substancial (percebido) entre a demanda e a capacidade de resposta (do indivíduo) em condições em que o fracasso diante desta demanda acarreta importantes consequências (percebidas)” (MTAS, 2007, Vol. I, p. 66) ou, por fim, como "uma interacção das condições de trabalho com as características do trabalhador em que as exigências do trabalho excedem a capacidade do trabalhador para lidar com elas” (Ross \& Altmaier, 1994, p. 12).

Está presente, em qualquer uma destas definições, a interação que existe entre o indivíduo e o ambiente de trabalho e a necessidade de procurar ajustar o mais possível os recursos dos indivíduos às exigências do trabalho. Para Leka, Griffiths e Cox (2003, p. 5), "quanto mais se ajustem os conhecimentos e as capacidades do trabalhador às exigências e pressões do trabalho, menor será a probabilidade de que o trabalhador sofra de stress", mas esse ajustamento deve ser visto como "sendo sempre modulado pela perceção que o indivíduo tem de si mesmo e do mundo" (MTAS, 2007, Vol. I, p. 66).

O exercício de uma atividade profissional está relacionado com a articulação entre os fatores sociais e psicológicos que influenciam o comportamento do sujeito e o desempenho na sua profissão. O stress não é então resultado de uma única origem, normalmente, este ocorre das características do trabalhador, do tipo de trabalho e das características da organização (Ribeiro, 2012). 
Estando o stress ocupacional cada vez mais presente nas organizações modernas, o trabalhador ao manter-se em stress de uma forma intensa e durante longos períodos de tempo pode levar a um quadro clínico crónico, gerando graves consequências a nível individual e a nível organizacional, criando elevados custos para as sociedades (Rosário, 2013).

Torna-se então fundamental elaborar ações de promoção da saúde e uma gestão preventiva do stress laboral, para se alcançar benefícios um bom nível de estado de saúde, assim e um elevado desempenho (Rosário, 2013).

Relativamente à intervenção, são três os níveis para prevenir o stress no contexto laboral: primário, secundário e terciário. A prevenção primária visa eliminar, ou tentar reduzir as causas do stress do ambiente de trabalho, reduzindo assim, as pressões instaladas sobre os trabalhadores (Cunha, Rego, Cunha, \& Cabral, 2007).

A intervenção secundária tem por objetivo atuar nos trabalhadores que apresentam alguns sintomas de stress para deste modo evitar que estes adoeçam (Paulos, 2009).

A prevenção terciária é direcionada aos trabalhadores que já apresentam problemas de saúde e de bem-estar devido ao stress ocupacional, visando proporcionar atividades de tratamento aos trabalhadores com problemas graves de saúde (reabilitação após um período de absentismo de longa duração, por exemplo).

Constata-se, assim, que é fundamental por parte das organizações a identificação não só das atividades que originam níveis elevados de stress, mas também dos trabalhadores que apresentam sintomas de stress (Rosário, 2013).

A prevenção deve, portanto, ser encarada como um processo contínuo, renovado e recriado, de acordo com as necessidades que vão surgindo ao longo da história da organização, devendo ser incorporada na cultura e procedimentos da organização (Ramos, 2001).

\subsection{Síndrome de Burnout}

A síndrome de burnout, também conhecida por síndrome de desgaste profissional, é um dos conceitos indissociáveis do stress profissional (GilMonte, \& Peiró, 1997; Paulos, 2009).

Não existe na literatura uma definição unanimemente aceite, pelo que se encontra diferentes definições do burnout, sendo a que reúne maior consenso a dos autores teorizadores desta síndrome, Maslach e Jackson (Coelho, 2009). Os autores definem o burnout como uma síndrome tridimensional, ou seja, deve ser concetualizada como uma síndrome de 
esgotamento emocional, despersonalização e falta de realização pessoal, devido ao prolongamento de situações de elevada exigência emocional no local de trabalho (Coelho, 2009; Rosário, 2013).

O esgotamento ou cansaço emocional refere-se aos sentimentos de perda e esgotamento dos recursos emocionais; a despersonalização/cinismo ou desumanização está relacionado com a adoção de atitudes e respostas negativas, frias e distanciadas na atividade profissional desempenhada; e a falta ou baixa realização pessoal traduz-se na diminuição dos sentimentos de competência e a falta de realização e de produtividade no trabalho (Coelho, 2009).

Para os autores Gil-Monte e Peiró (1997), o burnout surge no indivíduo como uma resposta ao stress ocupacional crónico. Se na definição de Maslach e Jackson o burnout é entendido como estado, as outras abordagens do burnout têm sido desenvolvidas enquanto processo. A abordagem enquanto processo diz respeito à resposta do stress profissional, provenientes quer das exigências ambientais quer da disparidade entre exigências e recursos, originando consequências ao nível individual e organizacional (Gonçalves, 2013).

A perspetiva psicossocial defende que a síndrome de burnout deve distinguir-se do stress psicológico, pois:

Enquanto no stress psicológico existe uma implicação exagerada nos problemas, uma hiperactividade emocional, o dano fisiológico é o fundamento principal, o esgotamento ou falta de energia é sobretudo física, a depressão produz-se como reacção para preservar as energias físicas e pode ter efeitos positivos em exposições moderadas (eustresse), na síndrome de burnout, existe falta de implicação, desgaste emocional, o dano emocional afecta a motivação e a energia física, a depressão traduz-se numa perda de ideais e só tem efeitos negativos (ISTAS, 2006, p. 14).

O stress seria então o resultado de uma tensão passageira, enquanto que a síndrome de burnout seria o resultado de tensões contínuas (Coelho, 2009). Verifica-se na literatura que é possível identificar diferentes preditores do burnout, como os fatores demográficos, de personalidade e organizacionais.

De salientar que a síndrome de burnout é mais frequente em determinadas profissões, sendo as profissões de saúde e a profissão docente, as de maior incidência (Rosário, 2013).

Dentro dos vários modelos de interpretação da síndrome de burnout e, de acordo com os fundamentos e as características destes, na caracterização e na prevenção da síndrome de burnout deve-se atender, por um lado, às teorias organizacionais, pois dão maior ênfase aos fatores de risco organizacionais: variáveis como a estrutura organizacional, o clima 
organizacional, o apoio social recebido e o desenvolvimento de estratégias eficazes para lidar com os stressores; e por outro, às teorias do intercâmbio social, que dão maior destaque à falta de competências sociais: exigências emocionais, falta de reciprocidade das relações e formas de organizar o trabalho emocional (Coelho, 2009).

\subsection{Assédio}

O assédio pode apresentar duas variáveis em contexto de trabalho: o assédio sexual e o assédio moral ou mobbing.

O assédio sexual e o assédio moral ou mobbing não são fenómenos recentes, mas sim algo que teve inicio desde que existe o trabalho e as relações laborais.

O assédio seja moral ou sexual pode ser praticado por superiores hierárquicos, colegas, clientes, representando um grave problema entre a população ativa europeia (Rosário, 2013).

O assédio sexual é um problema existente em qualquer contexto em que se desenvolvam relações humanas, sobretudo no contexto laboral, o qual pode originar violência física e psicológica.

Segundo a Diretiva 2004/113/CE, de 13 de dezembro de 2004, o assédio sexual pode ser definido como uma situação em que um comportamento indesejado de caráter sexual se manifesta sob a forma física, verbal ou não verbal, com o objetivo de violar a dignidade da pessoa e de criar um ambiente intimidativo, hostil, humilhante ou ofensivo.

Nas últimas décadas diversos autores têm procurado identificar quais os diferentes tipos de assédio sexual. McCann (2005, citado por Ribeiro, 2012) alude que existem três tipos de comportamento qualificados como assédio sexual: o comportamento físico como a violência ou contacto físico e uso de ameaças; o comportamento verbal como os comentários sobre a aparência física das vítimas, convites repetidos e observações sexuais; e o comportamento não-verbal como a exibição de imagens sexualmente explícitas.

Outra tipologia é proposta por Espinoza e Cunningham (2010, citados por Ribeiro, 2012) que dividem o assédio em dois tipos consoante a sua gravidade, o tipo de assédio mais grave e o menos grave. $\mathrm{O}$ mais grave compreende ameaças no trabalho para obtenção de favores sexuais, obrigar a vítima a um relacionamento não desejado e piadas sexuais. $\mathrm{O}$ assédio menos grave, diz respeito a comentários de natureza sexual, piropos e linguagem corporal ofensiva.

O assédio moral ou mobbing é entendido como uma interação social adversa não-ética que, é propositadamente exposta no ambiente de trabalho de uma forma metódica, normalmente por tempo prolongado, por uma ou mais pessoas contra dado trabalhador (Ribeiro, 2012). Comportamento de 
mobbing contínuo coloca o individuo numa situação de desespero, sem defesas e com um risco potencial de expulsão do seu emprego.

$\mathrm{O}$ assédio no local de trabalho abrange todo e qualquer comportamento abusivo que se exterioriza especialmente por palavras, atos, gestos, escritos, que consigam atingir a personalidade, a dignidade ou a integridade física ou psicológica de um indivíduo, colocando em risco o seu emprego ou o ambiente de trabalho (Hirigoyen,2002). O assédio surge de forma inofensiva e propaga-se insidiosamente. No início, os indivíduos não querem mostrar-se ofendidos e desconsideram algumas humilhações, mas depois esses ataques multiplicam-se e a vítima é constantemente inferiorizada, humilhada, hostilizada durante um longo período de tempo (Ribeiro, 2012).

Para Piñuel (2003), o assédio moral ou mobbing é então definido como um mau trato físico e verbal que um trabalhador está sujeito no seu local de trabalho e que ocorre de forma contínua e intencional com intuito de destruir a sua capacidade psicológica. Com isto, o trabalhador vê-se forçado a abandonar o seu local de trabalho, sendo muitas vezes este o intuito da organização.

$\mathrm{O}$ conceito de mobbing tem um fundamento ético que se refere à falta de estima pela dignidade de qualquer trabalhador, como elemento fundamental de uma relação laboral.

Este tipo de situação de stress no trabalho provoca lesões na autoestima do trabalhador, na qual este se sente perturbado, ameaçado, humilhado, desesperado e sem defesas. O mobbing é então um grave indutor de stress, provocando no indivíduo uma incapacidade de controlo da situação que está a ser vítima. Estas circunstâncias podem ter consequências muito graves para a saúde física e mental do ser humano e ainda repercussões importantes em relação ao emprego, condições sociais e económicas (Ribeiro, 2012).

No atual Código de Trabalho (Lei n. ${ }^{0} 7 / 2009$, de 12 de fevereiro) estão contempladas as definições de assédio moral (artigo 29..$^{\circ}$ n. $^{\circ} 1$ ) e sexual (artigo 29. ${ }^{\circ} .^{\circ}$ 2) e de igual modo, a penalização da prática do ato de ambas as naturezas, previsto pelo n. ${ }^{\circ} 4$ do artigo $29 .^{\circ}$ por tratar-se de uma contraordenação muito grave.

A prevenção do assédio nos locais de trabalho é um dos objetivos da Comissão Europeia, em conjunto com a estratégia comunitária de saúde e segurança (EU-OSHA, 2002c), tendo em conta a diretiva 89/391/CEE, estando prevista a responsabilidade das entidades patronais de assegurar a saúde dos trabalhadores, impedindo que sejam prejudicados por motivos relacionados com o trabalho, inclusivamente em virtude de assédio moral ou sexual. 


\subsection{Violência no Trabalho}

Nas últimas décadas, a violência no trabalho cresceu em virtude de várias circunstâncias, como o aumento das relações interpessoais no trabalho (Coelho, 2009), o que tem despertado preocupação e interesse nos investigadores, nos empregadores e instituições governamentais (Rosário, 2013).

O conceito violência no trabalho é definido pela Comissão Europeia como "qualquer incidente onde o profissional é ameaçado, abusado ou agredido em circunstâncias relacionadas com o seu trabalho, incluindo deslocações de e para o trabalho, que comprometem explícita ou implicitamente a sua segurança, bem-estar ou saúde” (EU-OSHA, 2007a, n.p.). Para a autora Paulos (2009), esta definição alude a três conceitos fundamentais: o comportamento abusivo, ameaças e ataques. Os comportamentos abusivos dizem respeito a comportamentos inadequados, associados à força física ou à pressão psicológica. As ameaças referem-se ao propósito de danificar o indivíduo e os seus bens materiais e por último, o ataque é uma tentativa de causar danos físicos a alguém.

Alguns fatores podem conduzir ao aumento do risco de violência no trabalho, tais como, o ambiente de trabalho, a cultura organizacional, o estilo de gestão e as condições de trabalho bem como as caraterísticas individuais do trabalhador (aptidão pessoal, qualificação profissional e conhecimento) (Rosário, 2013).

A prevenção da violência no local de trabalho é de importância vital, podendo implementar-se algumas práticas e medidas, tais como o estabelecimento de procedimentos disciplinares face a comportamentos inadequados, a exigências de tratar com respeito e dignidade tanto as chefias como os subordinados, bem como entre os trabalhadores, de forma a promover uma cultura de bem-estar e de segurança (Ribeiro, 2012).

A legislação portuguesa no que diz respeito à violência no trabalho ainda não tem nenhuma regulamentação específica, seja no âmbito da lei geral seja no âmbito da lei penal (Coelho, 2009).

\section{CONSEQUÊNCIAS DOS RISCOS PSICOSSOCIAIS}

Os riscos psicossociais em contexto laboral têm consequências negativas para a sociedade, para as organizações e para a saúde dos trabalhadores (ACT, 2012; ILO \& WHO, 2000; OIT, 2013a; OMS, 2005).

As consequências individuais podem afetar o indivíduo, nomeadamente ao nível físico, psicológico e mental (ACT, 2012).

Os riscos psicossociais podem ainda trazer consequências organizacionais, nomeadamente: desmotivação, aumento do absentismo, menor dedicação ao trabalho, aumento da rotatividade, menor 
produtividade, aumento do número de acidentes de trabalho, aumento das queixas dos utentes, deterioração da imagem institucional, aumento dos custos diretos e indiretos, mau ambiente psicológico nos locais de trabalho, aumento das situações de conflito, greves, agressões (ACT, 2012).

As consequências dos riscos psicossociais para a sociedade tem a ver, sobretudo, com a Saúde Pública, quer a nível da saúde física como mental dos indivíduos, e, em particular com a Saúde Mental no Trabalho (Coelho, 2009, OMS, 2001a, 2005, Rosário, 2013).

Apesar da saúde mental ser uma área de intervenção prioritária quer em Portugal, quer no resto da Europa, verifica-se que 97\% das despesas em saúde são gastas em tratamento e apenas 3\% é investido em prevenção da doença e promoção da saúde (European Comission, 2007). Tal demonstra uma falta de conhecimento dos custos da saúde mental e do reconhecimento da doença mental (Rosário, 2013). Sem dúvida que aumentando o investimento em medidas preventivas poderá reduzir-se o crescimento dos custos de saúde.

A saúde mental pode ser definida como "um estado de bem-estar em que o indivíduo é capaz de realizar o seu potencial, fazer face ao stresse normal da vida, trabalhar de forma produtiva e proveitosa, e dar o seu contributo em benefício da comunidade a que pertence” (OMS, 2009, n.p.). A OMS salienta ainda que "o bem-estar e a saúde mental nos locais de trabalho devem ser do interesse geral para todos os cidadãos, para todos os políticos e para todos os trabalhadores, bem como para todos os setores da sociedade". Torna-se evidente que a prevenção dos riscos psicossociais no trabalho é um dos pré-requisitos mais importantes para uma boa saúde mental e o bem-estar no trabalho (Rosário, 2013). Para a OMS, a saúde mental é o "estado de bem-estar que permite ao indivíduo realizar-se, lidar com as perturbações normais da vida, trabalhar produtiva e frutuosamente e contribuir para a vida da sua comunidade" (2001b, n.p.). Para OIT, o bem-estar é algo que se relaciona com o sentimento que o trabalhador apresenta no seu trabalho, com todos os aspetos da vida profissional, da qualidade e segurança do ambiente físico, o ambiente de trabalho e a organização do trabalho (EU-OSHA, 2013b). As medidas de bem-estar no local de trabalho têm como objetivo complementar as medidas de Segurança e Saúde no Trabalho (SST) para garantir a segurança, saúde e satisfação dos trabalhadores no trabalho.

Cada vez mais se verifica que o conceito de organização saudável adquire maior importância, reforçando a ideia de que um ambiente de trabalho saudável pode melhorar a saúde física e mental dos trabalhadores, a sua autoestima e qualidade de vida em geral (Rosário, 2013). 


\section{PREVENÇÃO E GESTÃOS DOS RISCOS PSICOSSOCIAIS}

A prevenção e promoção da saúde no trabalho pretende, por um lado, prevenir os riscos ocupacionais através da eliminação e/ou minimização dos seus efeitos negativos e, por outro, investir na promoção da saúde, cuja origem fundamenta-se nos aspetos positivos e de bem-estar no trabalho. Os efeitos positivos das políticas de prevenção de riscos no local de trabalho pode ser potenciado pelo incentivo e apoio aos trabalhadores e na adoção de estilos de vida que que contribuam para melhorar o seu estado geral de saúde. Desempenhando um papel central em todo o processo, os colaboradores de uma empresa têm de ser esforçar para a promoção da saúde no próprio local de trabalho. Deve-se reconhecer que o desenvolvimento e manutenção de um ambiente de trabalho saudável e força de trabalho tem claros benefícios para as empresas e funcionários, mas também pode conduzir a uma melhoria no desenvolvimento económico e social a nível nacional e europeu (EU-OSHA, 2013b).

Constata-se uma rápida transformação no mundo do trabalho associada a uma rápida evolução das condições de trabalho, do meio de trabalho, dos processos de trabalho e da organização do trabalho e processos legislativos lentos que não conseguem acompanhar a regulação da prevenção de novos riscos e perigos que resultam dessa mesma evolução (Rosário, 2013). Perante este cenário, é necessário criar condições de pro-atividade nas empresas quanto à melhoria das condições de trabalho, criar condições nas empresas para sistematicamente identificar, avaliar e controlar os riscos profissionais em constante evolução e por fim, criar condições de associação da melhoria das condições de trabalho com o crescimento e produtividade (Rosário, 2013). Os princípios gerais de prevenção constituem, por força do seu enquadramento na Diretiva-Quadro (89/391/CEE), o núcleo central da metodologia de prevenção que consta no conteúdo normativo da Lei n. ${ }^{\circ}$ 102/2009, de 10 de setembro, mais especificamente o artigo 15. ${ }^{\circ}$ da presente Lei (Cabral, 2011). Conforme o disposto no artigo 6. ${ }^{\circ}$ da Diretiva-Quadro, a respeito dos Princípios Gerais de Prevenção encontram-se elencados em seguida: $1 .^{\circ}$ Evitar os riscos; $2 .^{\circ}$ Avaliar os riscos que não podem ser evitados; $3 .^{\circ}$ Combater os riscos na origem; $4{ }^{\circ}$ Adaptar o trabalho ao Homem, especialmente no que se refere à conceção dos postos de trabalho, bem como à escolha dos equipamentos de trabalho e dos métodos de trabalho e de produção, tendo em vista, nomeadamente, atenuar o trabalho monótono e o trabalho cadenciado e reduzir os efeitos destes sobre a saúde; $5 .^{\circ}$ Ter em conta o estado da evolução técnica; $6 .^{\circ}$ Substituir o que é perigoso pelo que é isento de perigo ou menos perigoso; $7 .^{\circ}$ Planificar a prevenção como um sistema coerente que integre a técnica, a organização do trabalho, as condições de 
trabalho, as relações sociais e a influência dos fatores ambientais no trabalho; $8 .^{\circ}$ Dar prioridade às medidas de proteção coletiva em relação às medidas de proteção individual; 9. ${ }^{\circ}$ Dar instruções adequadas aos trabalhadores.

Para Cabral (2011), no âmbito dos nove princípios gerais de prevenção, a avaliação dos riscos constitui o elemento chave do processo de prevenção, atendendo ao fato de que dela depende o impulso de qualquer estratégia preventiva consequente. A legislação de segurança e saúde do trabalho confere à avaliação de riscos um lugar central nas abordagens preventivas, salientando ainda o autor que, essa centralidade deve-se à necessidade de conferir à prevenção uma linha de coerência que só se torna possível a partir de um conhecimento rigoroso e sistemático dos riscos que existem associados a qualquer local de trabalho e qualquer atividade produtiva. Assume-se que a avaliação de riscos é um processo dinâmico de forma a permitir uma adequada organização da prevenção dos riscos de acidente de trabalho e de doença profissional. No âmbito da prevenção de riscos ocupacionais considera-se gestão de riscos o processo sistemático mediante o qual se identificam os perigos, se analisam os riscos e se gerem os riscos e se protegem os trabalhadores (Cox, Griffiths, \& Cox, 1996).

A avaliação dos fatores psicossociais do trabalho e do seu impacto na saúde e segurança dos trabalhadores tem ganho um lugar de destaque, sendo cada vez mais reconhecido por instâncias governamentais.

\section{REFLEXÕES CONCLUSIVAS}

Nos últimos anos, as constantes mudanças nas organizações, devido às novas tecnologias e à organização e gestão do trabalho, e também a crise económica e o desemprego, tem aumentado os riscos psicossociais com consequências graves e negativas quer na saúde dos trabalhadores quer na diminuição do rendimento das empresas (Ribeiro, 2012).

Os riscos psicossociais, como o stress, o burnout, o assédio e a violência no trabalho são o desafio da Segurança e Saúde no Trabalho do século XXI. A segurança e a saúde no trabalho constitui um conjunto de finalidades que se obtêm pela prevenção dos riscos profissionais nos locais de trabalho (Rosário, 2013).

Cada vez mais, se deve encarar o local de trabalho como um espaço para promoção da saúde e de atividades preventivas da doença, com o intuito de não só evitar os acidentes de trabalho, mas também de proceder a avaliações e melhorias face a saúde geral das pessoas (WHO, 2010b).

Os riscos psicossociais no trabalho constituem um tema que, face às múltiplas transformações que têm acontecido no mundo laboral, e que por via de diferentes constrangimentos continuam a acontecer, continuará a ser 
uma preocupação em termos de riscos profissionais, nos próximos anos (Costa \& Santos, 2013). Neste domínio, a investigação poderá ser uma forma de conhecer os riscos psicossociais, os fatores que estão na sua origem e as suas consequências, para que seja possível o seu controlo e a prevenção dos seus efeitos.

A importância da investigação, reflexão e análise sobre os riscos psicossociais, é sem dúvida inegável e essencial para a construção de um corpo de saberes fundamentado que permita a prevenção destes riscos, a promoção dos efeitos positivos do trabalho e a garantia da saúde dos trabalhadores (Costa \& Santos, 2013).

\section{FONTES E BIBLIOGRAFIA}

Autoridade para as Condições do Trabalho - ACT (2012). Encerramento da Campanha de Avaliação de Riscos Psicossociais. Porto: Autoridade para as Condições do Trabalho.

Agência Europeia (2009). Promoção da Saúde Mental no Setor da Saúde E-Facts, 46.

Agência Europeia (2007). Expert forecast on emerging psychosocial risks related to occupational safety and health. Luxembourg: Office for Official Publications of the European Communities

Araújo, C., \& Rolo, D. (2011). Apresentação do dossier temático: Psicodinãmica e psicopatologia do trabalho laboral, 7 (1), 10-12.

Cabral, F. (2011). Segurança e Saúde do Trabalho. Manual de Prevenção de Riscos Profissionais. Lisboa: Verlag Dashöfer.

Canguilhem, G. (2009). O normal e o patológico. (6 $6^{\mathrm{a}}$ ed. rev.). Rio de Janeiro: Forense Universitária.

Cantera, L. M., Cervantes, G., \& Blanch, J. M. (2008). Violencia occupacional: el caso de los profesionales sanitarios. Papeles del Psicólogo, 29(1), 49-58.

CARIT (2012). Comité dos Altos Responsáveis das Inspecções do Trabalho. Campanha Europeia de Avaliação dos Riscos Psicossociais.

Coelho, J. M. A. (2009). Gestão Preventiva de Riscos Psicossociais no Trabaho em Hospitais no Quadro da União Europeia. Tese de Doutoramento em Ciências Sociais: Especiaização em Estudos Europeus, Universidade Fernando Pessoa. Porto.

Costa, L. S., \& Santos, M. (2013). Factores Psicossociais de Risco no Trabalho: Lições Aprendidas e Novos Caminhos. International Journal on Working Conditions, 39-58. 
Cox, T., \& Cox, S. (1993). Psychosocial and Organizational Hazards at Work: control and monitoring. Geneva: World Health Organization Regional Office.

Cox, T., \& Griffiths, A. J. (1995). The assessment of psychological hazards at work. In Shabracq, Winnubs, J.A., Cooper, C.L (Ed.). Handbook of work and the health psychology. Chichester Wiley \& Sons.

Cunha, M., Rego, A., Cunha, R., \& Cabral-Cardoso, C. (2007). Manual de Comportamento Organizacional e Gestão. Lisboa: Editora RH.

EU-OSHA (2002c). O assédio moral no local de trabalho. Facts n. 23. European Agency for Safety and Health at Work.

EU-OSHA. (2007a). Expert forecast on emerging psychosocial risks related to occupational safety and health. Luxembourg: Office for Official Publications of the European Communities.

EU-OSHA. (2010a). European Survey of Entreprises on New and Emerging Risks: managing safety and health at work . Luxembourg: Office for Official Publications of the European Communities.

EU-OSHA. (2013b). Well-being at work: creating a positive work environment. Luxembourg: Publications Office of the European Union.

European Commission (2007). Together for health: a strategic approach for the UE 2008-2013. Brussels: European Comission.

European Commission (2010). Investing in well-being at work Addressing psychological risks in times of change. Luxembourg: Publications Office of the European Union.

Ganem, V. (2011). Relato de uma experiência de terreno de intervenção em psicodinâmica do trabalho (PDT). Laboreal, 7 (1), 68-75.

Gil-Monte, P., \& Peiró, J. (1997). Desgaste psíquico en el trabajo: el síndrome de quemarse. Madrid: Editorial Síntesis, S.A.

Gollac, M., \& Bodier M. (2011). Mesurer les facteurs psychosociaux de risque au travail pour les maîtriser (Relatório do Collège d'Expertise sur le Suivi des Risques Psychosociaux au Travail).

Gonçalves, P. (2013). O stress e o bem-estar no trabalho. Lisboa: Sociedade Portuguesa de Medicina do Trabalho.

Hirigoyen, M. (2002). O assédio no trabalho: como distinguir a verdade. Cascais: Editora Pergaminho.

ILO, \& WHO. (2000). Mental Health and Work: Impact, Issues and Good Practices. Geneva: World Health Organisation.

Leka, S., \& Cox, T. (2008). The European Framework for Psychosocial Risk Management: PRIMA-EF. Geneva: World Health Organization.

Leka, S., Griffiths, A., \& Cox, T. (2003). Work Organization and Stress. Geneva: World Health Organization. 
OIT - Organização Internacional do Trabalho (1986). Les facterurs psychosociaux au travail. Nature, incidences, prévention. Bureau International du Travail. Genève.

OIT (2013a). A Prevenção das Doenças Profissionais. Dia Mundial da Segurança e Saúde no Trabalho: 28 de Abril 2013. Lisboa: Organização Internacional do Trabalho.

OMS - Organização Mundial da Saúde (1981). Santé et bien-être sur les lieux de travail. Rapport sur la réunion d'un groupe de travail de l'OMS. Prague, le 18-20 septembre 1979. Bureau Régional de l'Europe. Copenhague. Organisation Mondiale de la Santé.

OMS (2001a). Mental Health: a Call for Action by World Health Ministers. Geneva: World Health Organization.

OMS (2001b). Strengthening mental health promotion. (Factsheet n. ${ }^{\circ 220) .}$ Geneve: World Health Organisation.

OMS (2005). Mental Health: facing the challenges, building solutions. Geneva: World Health Organization.

OMS (2009). Mental Health Definition. Acedido em 24 de Junho de 2013.

Paulos, C. (2009). Riscos Psicossociais no Trabalho. Lisboa: Verlag Dashöfer.

Piñuel, I. (2003). Mobbing: Como sobrevivir al acosso psicológico en el trabajo. Madrid: Santillana Ediciones Generales, S.L.

Ramos, M. (2001). Desafiar o desafio: Prevenção do stress no trabalho. Lisboa: RH Editora.

Ribeiro, M. F. A. (2012). Riscos Psicossociais no Trabalho dos Enfermeiros. Dissertação de Mestrado em Enfermagem de Reabilitação, Instituto Superior Politécnico de Viseu, Escola Superior de Sáude. Viseu.

Rosário, K. A. R. (2013). Validação e adaptação linguística e cultural da versão longa do Questionário Copenhagen Psychosocial Questionnaire II (COPSPQ II) em portugês. Dissertação de Mestrado em Engenharia de Segurança e Higiene Ocupacionais, Universidade do Porto, Faculdade de Engenharia. Porto.

Ross, R. R., \& Altmaier, E. M. (1994). Intervention in Occupational Stress. A Handbook of Counselling for Stress at work. London. Sage Publications.

WHO (2010b). Healthy workplaces: a model for action For employers, workers, policy-makers and practitioners. Geneva: World Health Organization. 